\title{
Jau-Dignac et Loirac - La Chapelle
}

Isabelle Cartron et Dominique Castex

URL : http://journals.openedition.org/adlfi/7759

ISSN : 2114-0502

Éditeur

Ministère de la culture

\section{Référence électronique}

Isabelle Cartron et Dominique Castex, " Jau-Dignac et Loirac - La Chapelle », ADLFI. Archéologie de la France - Informations [En ligne], Aquitaine, mis en ligne le 01 mars 2007, consulté le 19 avril 2019. URL http://journals.openedition.org/adlfi/7759

Ce document a été généré automatiquement le 19 avril 2019

(c) Ministère de la Culture et de la Communication, CNRS 


\title{
Jau-Dignac et Loirac - La Chapelle
}

\author{
Isabelle Cartron et Dominique Castex
}

Identifiant de l'opération archéologique : 2007

Date de l'opération : 2007 (FP)

1 Le site de "La Chapelle » est en cours de fouille depuis 2001. Après une interruption en 2006, une nouvelle opération, programmée pour trois ans, a débuté en 2007. La succession des phases d'occupation de cet ancien îlot des bords de l'estuaire de la Gironde est désormais bien établie.

2 Un temple gallo-romain est d'abord fondé au $\mathrm{I}^{\mathrm{er}} \mathrm{s}$. sur cette partie septentrionale de l'île ; il est abandonné lentement vers la fin du $\mathrm{IV}^{\mathrm{e}} \mathrm{s}$. Les ruines de ce temple sont réaménagées ce qui témoigne d'un grand changement dans la fonction du site. Le hiatus est évident, mais la réoccupation n'est pas fortuite et tient compte de la présence de bâtiments anciens dont on pouvait tirer parti, tant du point de vue matériel que symbolique.

3 En effet, ce sont probablement les membres d'une riche famille aristocratique qui ont transformé cet espace pour en faire une nécropole patrimoniale au sein de laquelle les ruines sont converties en une petite église abritant une douzaine de sépultures assez prestigieuses. La découverte majeure de la campagne de 2007 est celle du chevet rectangulaire de l'église patrimoniale qui permet de définir sans ambiguïté la fonction de l'édifice mérovingien qualifié jusqu'alors de bâtiment funéraire (Cartron, Castex, 2006).

Il s'agit donc d'un lieu de culte chrétien lié à la mise en place d'un espace funéraire familial. On note le changement qu'introduit ce monument dans l'utilisation de la nécropole puisque plusieurs sépultures viennent alors s'accoler au chevet, assurément perçu comme l'endroit le plus attractif pour les défunts. On notera d'ailleurs que les sépultures se répartissent autour de l'édifice sur un rayon d'environ une dizaine de mètres. Dans son ensemble, la nécropole du haut Moyen Âge regroupe pour le moment au moins 55 individus pour un peu moins de quarante sépultures.

Deux modes d'inhumations ont été employés pour l'ensemble des sépultures. Les sarcophages situés à l'intérieur de l'édifice semblent attribuables à la première période de 
fonctionnement de l'église (fin $\mathrm{VI}^{\mathrm{e}} \mathrm{s}$. et $\mathrm{VII}^{\mathrm{e}} \mathrm{s}$.), en relation directe avec sa construction : il s'agit d'abriter les sépultures des ancêtres prestigieux de la familia.On note aussi la présence de contenants en bois, plus nombreux aux abords de l'église. Ces datations suggèrent une utilisation assez longue de la nécropole jusqu'à l'époque carolingienne. D'autres datations radiocarbone sont envisagées pour affiner ce terminus.

La présence d'un petit habitat (XI ${ }^{\mathrm{e}}$ s.-XII ${ }^{\mathrm{e}} \mathrm{s}$. ?) venant s'installer sur les ruines atteste de l'intensité de l'occupation de l'îlot. La construction de la chapelle médiévale n'apparaît donc pas en continuité avec l'ancienne église qui avait alors été détruite. La présence d'anciennes sépultures a pu alors contribuer à l'édification d'un lieu de culte chrétien à cet emplacement vers le début $\mathrm{du}_{\mathrm{XIII}}^{\mathrm{e}} \mathrm{s}$. auquel une trentaine de tombes a été associée sans grande certitude.

7 (Fig. $\mathrm{n}^{\circ} 1$ : Plan de la nécropole et de l'église du haut Moyen Âge)

8 Cartron Isabelle, Castex Dominique

\section{ANNEXES}

Fig. $\mathrm{n}^{\circ} 1$ : Plan de la nécropole et de l'église du haut Moyen Âge

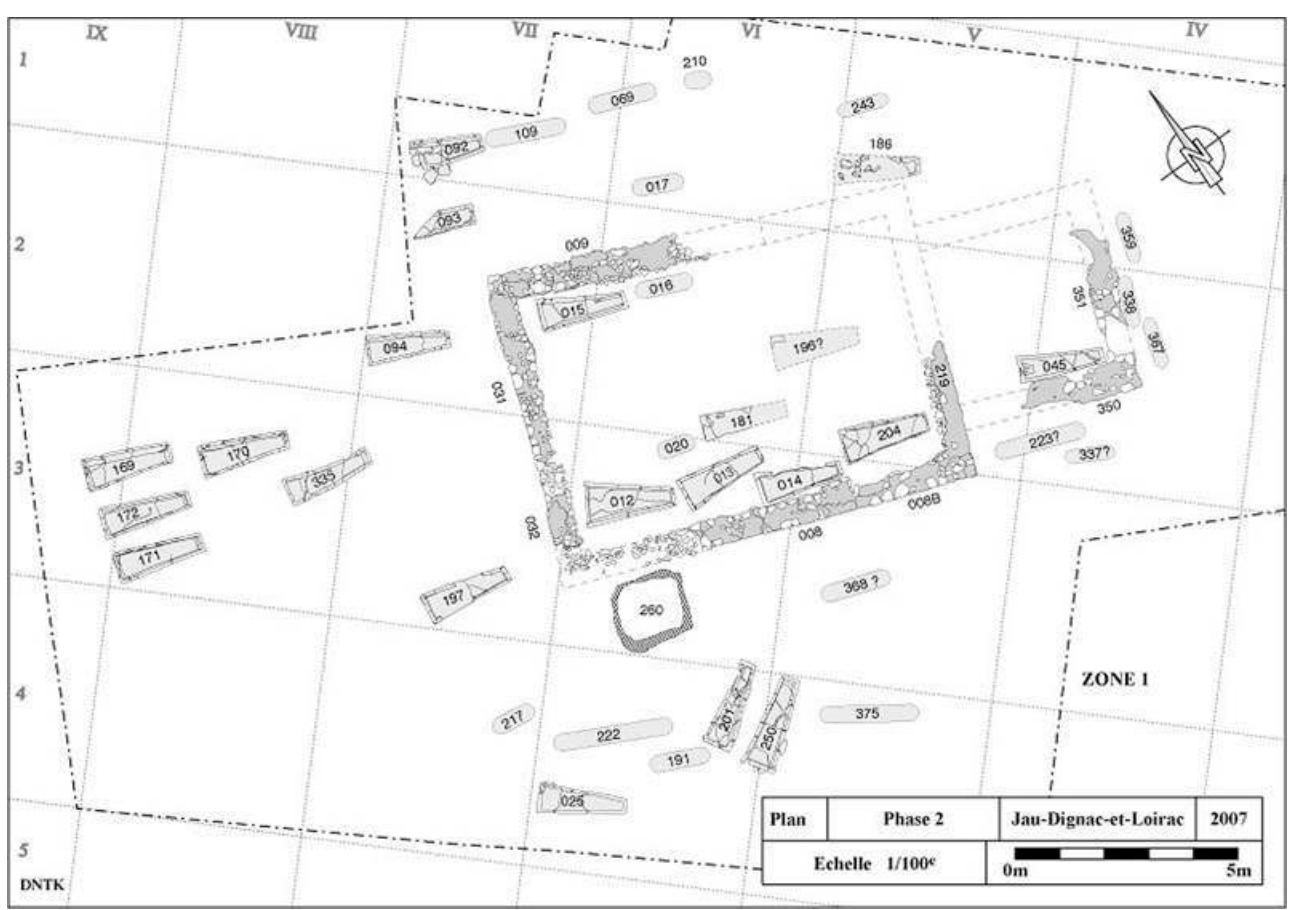

Auteur(s) : Boyer, D. ; Kawe, D.. Crédits : D. Kawe ; D. Boyer (2007) 
INDEX

operation Fouille programmée (FP)

Index chronologique : Empire romain, ép. carolingienne, ép. mérovingienne, Moyen Âge Index géographique : Aquitaine, Gironde (33), Jau-Dignac-et-Loirac (33208)

Thèmes : aristocratie, chevet, église, habitat, lieu de culte, nécropole, radiocarbone, sépulture, temple

\section{AUTEURS}

ISABELLE CARTRON

SUP 